\title{
An Empirical Analysis of Factors Affecting on Preference for Cashew in Nipani
}

\author{
Vivek Mahajan', Dr. Pravin Chavan² \\ ${ }^{1}$ Post Graduate Student, ${ }^{2}$ Assistant Professor \\ ${ }_{1,2}$ Chhatrapati Shahu Institute of Business, Education \& Research, Kolhapur, Maharashtra, India
}

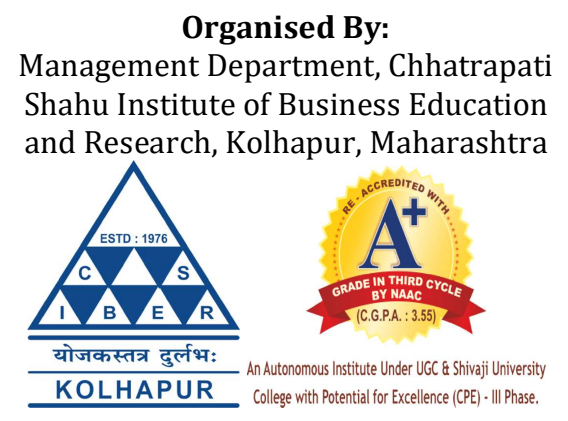

How to cite this paper: Vivek Mahajan | Dr. Pravin Chavan "An Empirical Analysis of Factors Affecting on Preference for Cashew in Nipani" Published in International Journal of Trend in Scientific Research and Development (ijtsrd), ISSN: 2456-6470, Special Issue | Fostering Innovation, Integration and Inclusion Through Interdisciplinary

Practices in

Management, March 2019, pp.207-211, URL:

https://www.ijtsrd. com/papers/ijtsrd2 3104.pdf

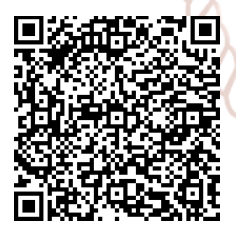
IITSRD23104

\section{ABSTRACT}

Cashew is one of the important dry fruit gaining popularity in the recent past. As information regarding dry fruits is hardly available, the recognition of consumers' preference for cashew was undertaken. This study was conducted during the year 2018 in Nipani city. The main objective of the study was to study factors influencing on selection of cashew. The primary data was collected from 120 cashew consumers through questionnaire. The data was analyzed by tabular analysis, factor analysis, One Way ANOVA test and descriptive statistics. The result revealed that major factors influencing for cashew preference was reasonable price, taste and quality. The factor analysis result revealed that convenience factor, recommendation factor and quality factor has more influence on the consumers for the cashew preference. The hypothesis result revealed that there is no correlation between preference for cashew and annual income of the consumers.

\section{KEYWORDS: Dry fruit, cashew, preferences}

\section{INTRODUCTION}

Four centuries ago, when the adventurous Portuguese landed on the Indian coasts, they brought with them the valuable tree nut, cashew. Cashew came, conquered and took deep roots in the entire coastal region of India. It found that the Indian soil more suitable for cashew growth than its homeland-Brazil. Later it soon spread as a popular cash crop to other parts of India. Cashew is one of the important commercial crops in India, and India has over 700,000 ha. Cashew plantation and has annual output of over 400,000 tons of raw cashew nuts.

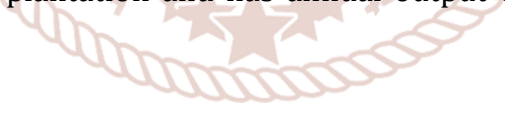

Cashew is grown in the western and eastern coastal areas and further island, and the major production states are Kerala, Andhra, Orissa, Maharashtra, Karnataka, Goa and Tamil Nadu; Meghalaya, Madhya Pradesh also have a small amount of production. India is the largest grower, processor and exporter in the world. It is also interesting to understand, that the new statistics of consumer interests done during 2009 has proved India is also the number one consumer of cashew kernels in the world overtaking USA. Cashew kernels is consumed all over the world as a premium snack and nowadays more used as a preferred ingredient due to its excellent flavor and unique texture in large array of foods like sweets, dates, ice-creams and so on. (Chen)

\section{CONCEPTUAL BACKGROUND}

Consumer Buying Behavior: Consumer behavior involves the study of individuals and the method they employ to choose, utilize, and set out products and services to fulfill their wants and the effect that these method have on the consumer and the society as a whole. Consumer behavior refers to all the thought, feelings and actions that an individual has or takes before or while buying any product, service or idea. Buyer behavior is the concept which answers what, why, how, when, and where an individual makes purchase. As a result, the outcome of buyer behavior is the buyer's decision. The entire purchasing process involves giving a thought on what should be bought, which brand is good or suitable, from where or whom should the purchase be made, when to purchase, how much to spent, and how many time to buy and in what intervals. Consequently the end result of the buyer behavior is the customer's final decision regarding the product choice, brand choice, dealer choice, purchase timing, purchase amount and purchase frequency (Khaniwali, 2015). 


\section{LITERATURE REVIEW}

Mohammad Hamed Khusrawy (2011) studied consumer behavior for dry fruits in Bangalore city. The study revealed that 64 percent of the consumers are aware of dry fruits brands. The highest consumer preference was for Dates, Almonds and Cashews. More than 58 percent of the consumers preferred branded dry fruits and remaining 42 percent preferred unbranded dry fruits. The important factors influencing purchasing of dry fruits are health, taste and quality. The consumption of dry fruits was mainly in the Morning.

Shaw (1993) studied the consumption pattern of processed food in Delhi. The study revealed that easy availability, taste and easy to store qualities of the processed products were more popular in buying decisions of the consumers. Major factors which influenced buying decisions of consumers were brand name, government certification and price of the product. He noticed that processed food products were boon to busy hou sewife as it made cooking simple and saved time.

Katarzyna Jesionkowska, Siet Sijtsema, Ronan Simoneaux, Dorota Konopacka and Witold Płocharski (2008) studied on preferences and consumption of dried fruit among Dutch, French and Polish consumers and they came up with an interesting conclusion that dried fruits as well as dried fruits products are eaten occasionally. Majority of the respondents declared that they eat dried fruits once a day or few times a week. Raisins occurred to be the most preferred fruit not only for Dutch but also for French and Polish respondents whereas breakfast cereals occurred to be one of the most preferable products. In the consumption context, Dutch and French respondents consumed dried fruits mainly in the morning, whereas Polish respondents claimed they eat dried fruits in the afternoon and evening in the form of snack while watching the TV.

Jon and Garrett (2006) studied on consumer preferences for cluster raisins: A Focus Group Investigation, findings included that a young age group of $18-25$ years market segment would be a target market and also made recommendations regarding price, packaging, and methods of increasing consumer awareness. Recommended marketing channels include specialty markets like Trader Joe's or Whole Foods and gift baskets.

Radha Mohan Jangir (2010) studied the consumer preference for processed fruit and vegetable products in Jaipur city, Rajasthan. The study revealed that consumers expressed high preference to the quality of the product, followed by its price, taste, keeping quality, ready to eat form; neighbors use it, easy availability and also the preference of the family members while selecting a particular brand.

Singh et al. (1995) considered factors namely quality, availability, convenient pack size, flavour, colour, freshness and mode of payment to study the preference for a particular source of milk namely, rural milk vendors, privately owned city dairies and dairy factories. The results said that 70 per cent of the respondents preferred milk supplied by city dairies. The least preferred was that sold by dairy factories.

Sharma (1997) studied the factors determining consumer's acceptance and preference for food in general. Many factors combine and interact to make buying a process complex. Price was identified as an important factor; however it had some limitations on the consumer's choice. Factors like sensory attributes regional preference, age, sex, interest, motivation, discrimination and income also influenced food consumption.

\section{RESEARCH OBJECTIVE}

To study the factors affecting on preference for cashew in Nipani.

\section{HYPOTHESIZES TESTING}

Following hypothesizes were framed to study the relationship of factors affecting on preference for cashew with annual income of the customer.

\section{Hypothesis 1}

$\mathrm{H}_{0}$ : Factors affecting on preference for cashew is independent to the Annual Income

$\mathrm{H}_{\mathrm{a}}$ : Factors affecting on preference for cashew is dependent to the Annual Income

\section{RESEARCH METHODOLOGY}

Collection of Data: Data was collected using structured questionnaire. The primary data was collected from 120 consumers of Nipani. The primary data regarding to the study was collected by personally interviewing the respondents using a structured questionnaire.

Data Collection: The study is descriptive and diagnostic in its nature. It intends to describe the factors that influence on consumer decision for cashew purchasing and whether the importance given to the particular factor differs to the income of the consumer.

To test the stated hypothesis primary data was collected through structured questionnaire. The factors that influence on consumer purchase decision were identified through strong literature review. The respondents were asked to grade the statement in terms of five point scale, where 1 represent highly unimportant and 5 represent highly important.

Sampling Design and Sample Size: The study was conducted in Nipani City. The population under study was infinite as it is difficulty to identify the people purchasing cashew. Hence sampling method for the study was convenience sampling. Total 120 respondents have filled the questionnaire and it was sample under the study.

Data Analysis: For analysis MS office Excel and SPSS 20.0 was used. To understand the factors influencing on consumer decision for purchasing a cashew principle component analysis was run on scale prepared to understand the factors influencing on purchase of cashew. Reliability of the items score under each factor was assessed using Cronbach alpha index. Finally, ANOVA was used to test the stated hypothesis.

\section{ANALYSIS AND DISCUSSION:}

The important objective of this research work is to identify the factors influencing on purchase of cashew. Here with a thorough literature review ten statements were identified and respondents were asked to rank those statements in terms of the importance they five while purchasing the 
International Journal of Trend in Scientific Research and Development (IJTSRD) @ www.ijtsrd.com eISSN: 2456-6470

cashew. Here five point rating scale was used where 1-Not at all Important, 2-Not so Important, 3-Moderately Important, 4-Somewhat Important and 5-Very Important. Factor analysis was used to identify the significant factors influencing on contributing to consumer behavior.

\section{Factor Analysis}

Table No. 1: KMO and Bartlett's Test

\begin{tabular}{|c|c|c|}
\hline \multicolumn{2}{|c|}{$\begin{array}{c}\text { Kaiser-Meyer-Olkin Measure of } \\
\text { Sampling Adequacy. }\end{array}$} & .642 \\
\hline \multirow{3}{*}{$\begin{array}{c}\text { Bartlett's Test of } \\
\text { Spheri city }\end{array}$} & $\begin{array}{c}\text { Approx. Chi- } \\
\text { Square }\end{array}$ & 381.131 \\
\cline { 2 - 3 } & df & 45 \\
\cline { 2 - 3 } & Sig. & .000 \\
\hline
\end{tabular}

To test the sampling adequacy KMO (Kaiser-Meyer-Olkin Measure of Sampling Adequacy) test was performed. KMO test statistic score is 0.642 . The Barlett's Test of Sphericity testing for the significance of the correlation matrix of the variables indicates that the correlation coefficient matrix is significant as indicated by the p-value(0.00) corresponding to the chi-square statistic.

The sample size of 120 is more than 5 times the number of variables (ten). All these justify the use of factor analysis for the given set of data (Chawla \& Sondhi, 2016).

\section{Factor Extraction:}

Table No. 2: Factor Extraction

\begin{tabular}{|c|c|c|c|c|c|c|c|c|c|}
\hline \multicolumn{10}{|c|}{ Total Variance Explained } \\
\hline \multirow{2}{*}{ Component } & \multicolumn{3}{|c|}{ Initial Eigen values } & \multicolumn{3}{|c|}{$\begin{array}{l}\text { Extraction Sums of Squared } \\
\text { Loadings }\end{array}$} & \multicolumn{3}{|c|}{$\begin{array}{l}\text { Rotation Sums of Squared } \\
\text { Loadings }\end{array}$} \\
\hline & Total & $\begin{array}{c}\% \text { of } \\
\text { Variance }\end{array}$ & $\begin{array}{c}\text { Cumulative } \\
\%\end{array}$ & Total & $\begin{array}{c}\% \text { of } \\
\text { Variance }\end{array}$ & $\begin{array}{c}\text { Cumulative } \\
\%\end{array}$ & Total & $\begin{array}{c}\% \text { of } \\
\text { Variance }\end{array}$ & $\begin{array}{c}\text { Cumulative } \\
\%\end{array}$ \\
\hline 1 & 3.471 & 34.709 & 34.709 & 3.471 & 34.709 & 34.709 & 2.235 & 22.350 & 22.350 \\
\hline 2 & 1.486 & 14.860 & 49.569 & 1.486 & 14.860 & 49.569 & 2.112 & 21.123 & 43.473 \\
\hline 3 & 1.390 & 13.900 & 63.469 & 1.390 & 13.900 & 63.469 & 2.000 & 19.996 & 63.469 \\
\hline 4 & .899 & 8.989 & 72.457 & $\operatorname{lin} 3$ & $101 / \mathrm{d} / \mathrm{f} / \mathrm{C}$ & 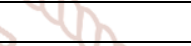 & & & \\
\hline 5 & .724 & 7.244 & 79.702 & \begin{tabular}{|l|}
$0^{\circ}$ \\
\end{tabular} & 0000 & & & & \\
\hline 6 & .595 & 5.955 & 85.657 & & & & & & \\
\hline 7 & .520 & 5.198 & 90.855 & & 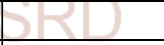 & e & & & \\
\hline 8 & .382 & 3.821 & 94.676 & & & 38 & & & \\
\hline 9 & .339 & 3.392 & 98.068 & titate & IIAा Jut & का & & & \\
\hline 10 & .193 & 1.932 & 100.000 & Trend & In Scient & IC $=$ & & & \\
\hline
\end{tabular}

The above table shows all the factors extractable from the analysis along with their Eigen values, the percent of variance attributable to each factor, and the cumulative variance of the factor and the previous factors. To choose the criteria of Eigen values over 1 is used. Here three factors have Eigen values greater than 1. The Eigen values for three factors are 3.471, 1.486 and 1.390 respectively. The percentage of the total variance is used as an index to determine how well the total factor solution accounts for what the variables together represent. The index for the present solution accounts 63.469 percent of the total variations for customers' cashew preference. It is pretty good extraction as it can economize on the number of factors (from ten to three factors).

The factor extraction can be easily illustrated by using Scree Plot (Graph No. 1)

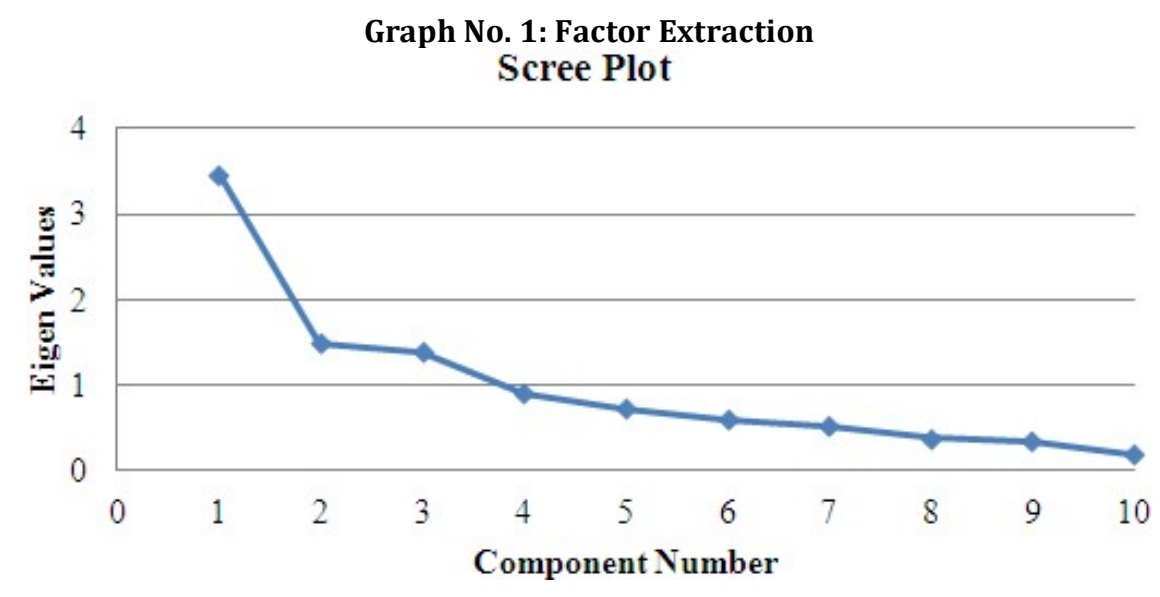

The point of interest for factor extraction is where the curve starts to flatten. In the Graph No. 1, the curve starts flatten from component number 4 to component number 10 . The Eigen value for the component number 4 is less than 1 . The first three, component number 1, 2 and 3 has Eigen value more than 1. Therefore, three factors were extracted which are having influence on consumer cashew preference. 
International Journal of Trend in Scientific Research and Development (IJTSRD) @ www.ijtsrd.com eISSN: 2456-6470

Above table shows the loadings of the ten variables on three factors extracted. The higher the absolute value of the loading, the more the factor contributes to the variable. Based on the pattern of factor loading, labels were assigned to the factors. Table No.4 gives the details of the items three factors identified and the item under each factor with its mean score, standard deviation and reliability alpha score.

Table No. 4: Grouping of Recommendation Factor

\begin{tabular}{|c|c|c|c|c|}
\hline Factor Name & Variables & Mean & $\begin{array}{l}\text { Standard } \\
\text { Deviation } \\
\end{array}$ & $\begin{array}{c}\text { Cronbach's Alpha Reliability } \\
\text { Score }\end{array}$ \\
\hline \multirow{4}{*}{$\begin{array}{l}\text { Recommendation } \\
\text { Factor }\end{array}$} & $\begin{array}{l}\text { Family members } \\
\text { recommendation }\end{array}$ & 3.67 & 1.079 & \multirow{4}{*}{0.714} \\
\hline & Attractive packaging & 3.72 & 0.927 & \\
\hline & Friends recommendation & 3.60 & 1.095 & \\
\hline & Brand Image & 4.00 & 0.789 & \\
\hline \multirow{3}{*}{ Convenience Factor } & Size of Cashew & 3.47 & 1.188 & \multirow{3}{*}{0.719} \\
\hline & Quantity & 3.89 & 1.052 & \\
\hline & Availability & 3.91 & 0.756 & \\
\hline
\end{tabular}

Factor analysis has revealed the following factors that influence on purchasing bakery products.

Recommendation Factor: Recommendation is the important factor that influence on purchase of cashew brand. Brand image and Attractive packaging are non-human recommendation whereas family members' recommendation and friends' recommendation are human recommendation.

Convenience Factor is the next factor which explains 14.860 percent of the variables. This factor explains that consumers' preference for cashew which is more convenience to them. The consumers prefer and buy those cashew brands which are widely available in the market, having wide variety in the size of cashew and available in the desired quantity.

Quality Factor This factor explains that the prices of the cashew vary from day to day/year to year. At a particular time prices vary according to the taste and quality of the cashew. Better the taste and high quality, higher the price and vice versa. Reasonable price, taste and quality of the cashews are interdependent to each other.

\section{HYPOTHESIS TESTING}

Hypothesis Test between Factors affecting on preference for cashew and Annual Income of the consumers

$\mathbf{H}_{\mathbf{0}}$ :Factors affecting on Preference for cashew is independent to the Annual Income

$\mathbf{H}_{\mathbf{a}}$ :Factors affecting on Preference for cashew is dependent to the Annual Income

To test the stated hypothesis ANOVA test was used. Analysis of variance (ANOVA) is a statistical procedure concerned with comparing means of several samples. Here respondents were classified in terms of their income such as income upto 3 lakh, 3 lakh to 5 lakh, 5 lakh to 10 lakh and more than 10 lakh. It is checked whether the factors influencing on the purchase of cashew differs to their income.

Table No. 8: One Way ANOVA results for Factors affecting on preference of cashew

\begin{tabular}{|c|c|c|c|c|c|c|}
\hline \multicolumn{9}{|c|}{ ANOVA } & Sum of Squares & df & Mean Square & F & Sig. \\
\hline \multirow{3}{*}{ Convenience Factor } & Between Groups & .765 & 3 & .255 & .366 & .778 \\
\cline { 2 - 7 } & Within Groups & 75.196 & 108 & .696 & & \\
\cline { 2 - 7 } & Total & 75.961 & 111 & & & \\
\hline \multirow{3}{*}{ Recommendation Factor } & Between Groups & .666 & 3 & .222 & .405 & .750 \\
\cline { 2 - 8 } & Within Groups & 59.253 & 108 & .549 & & \\
\cline { 2 - 8 } & Total & 59.920 & 111 & & & \\
\hline \multirow{3}{*}{ Quality Factor } & Between Groups & .882 & 3 & .294 & 1.595 & .195 \\
\cline { 2 - 8 } & Within Groups & 19.912 & 108 & .184 & & \\
\cline { 2 - 8 } & Total & 20.794 & 111 & & & \\
\hline
\end{tabular}

Here P-value for all these three factors convenience factor $(\mathrm{P}-$ Value $=0.778)$, recommendation factor $(\mathrm{P}-\mathrm{value}=0.750)$ and quality factor(P value $=0.195$ ) is greater than $5 \%$ level of significant. The hypotheses testing result reveals that the importance given by the customers for purchasing of cashew is independent of their annual income.

\section{FINDINGS}

1. Among the consumers the important factors influencing purchasing of cashew were reasonable price, taste and quality.

2. Findings based on Factor analysis results:
A. The overall mean of Convenience factor is 3.76 . Availability of cashew is contributing most to the convenience variable and has 3.91 mean. Quantity and size of cashew also describes as convenience factor. 
International Journal of Trend in Scientific Research and Development (IJTSRD) @ www.ijtsrd.com eISSN: 2456-6470

B. The overall mean of Recommendation factor is 3.75 Brand Image and Attractive packaging are considered as Non-Human Recommendation factors where as Family member's recommendation and Friend's recommendation are considered as HumanRecommendation factors. Brand Image shows the most recognize variable of recommendation factor and has the highest mean 4.00.

C. The total mean of Quality factor is 4.67. Taste is the most considered quality factor by consumers and has the highest mean of 4.79. Quality as well as Reasonable price also describes as quality factor.

3. Findings based on Hypothesis testing results:

A. It is found that there is no correlation between the preference for cashew and annual income of respondents.

I. There is no correlation between convenience preference and annual income of respondents.

II. There is no correlation between recommendation preference and annual income of respondents.

III. There is no correlation between quality preference and annual income of respondents.

\section{CONCULSION}

In this study the preference for cashew is examined by the help of questionnaires directed to the cashew buyers in Nipani. The preference for cashew is affected by Convenience factor, Recommendation factor and Quality factor. Among all ten variables studied quality, taste and reasonable price have higher cashew preference among consumers. Therefore, the processors of the cashew should first focus on the quality factor and provide the cashew to the customers with high quality. The three factors i.e. convenience factor, recommendation factor and quality factor affecting the consumer buying behavior towards the cashew does not differ to their annual income. It means the consumer cashew preference is independent to their annual income.

\section{Reference}

[1] Aczel, A. D. (1989). Complete Business Statisitcs. Richard d lrwin.

[2] Chen, L. (n.d.). LinkedIn. Retrieved January 27, 2016 from LinkedIN: https://www.linkedin.com/pulse/informationcashew-processing-india-lana-chen
[3] CronbachLJ. (1951). Coeficient alpha and the internal structure of tests. Psychometrika , 297-334.

[4] Jangir, R. M. (2010). AN ANALYSIS OF CONSUMER PREFERENCE FOR PROCESSED FRUIT AND VEGETABLE PRODUCTS IN JAIPUR CITY, RAJASTHAN.

[5] Jesionkowska, K., Sijtsema, S., Simoneaux, R., Konopacka, D., \& Płocharski, W. (2008). Preferences And Consumption of Dried Fruit And Dried Fruit Products Among Dutch, French And Polish Consumers. Journal of Fruit and Ornamental Plant Research , 261274.

[6] Jon, C., \& Garrett, R. (2006). Consumer PReferences for Cluster Raisins: A Focus Group Investigation . Pomona: California State Polytechnic University.

[7] Khaniwali, M. (2015). Consumer Buying Behavior. International Journal of Innovation and Scientific Research , 278-286.

[8] Khusrawy, M. H. (2011). Consumer Behaviour For Dry Fruits In Bangalore City. Bangalore: University of Agricultural Sciences.

[9] Malhothra, L. N., Singh, P. K., \& Sanghera, P. K. (1995). Nutritive value and consumption pattern of some milk and milk products. Indian Dairy Management, 32(4): 47-51.

[10] Montgomery, D. C., \& Runger, G. C. (2003). Applied Statistics and Probability for Engineers. John Wiley \& Sons.

[11] Sharma, D. K. (1997). Consumer acceptance studies. Indian Dairy Management , 49(2): 27-31.

[12] Shaw, A. M., \& Malhothra, N. N. (1993). A study of consumer attitudes towards processed foods. Indian Food Packer, 29-41.

Copyright (c) 2019 by author(s) and International Journal of Trend in Scientific Research and Development

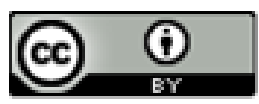
Journal. This is an Open Access article distributed under the terms of the Creative Commons Attribution License (CC BY 4.0) (http://creativecommons.org/licenses/by/4.0) 